\title{
DEVELOPMENT AND APPLICATION OF REMOVABLE VARNISH FOR WALL PROTECTION PAINT COATING BOOTHS
}

\author{
${ }^{1}$ Veniamin BOLDYREV, ${ }^{2,3}$ Vladimir MEN'SHIKOV, ${ }^{2}$ Anastasiya SAVINA, ${ }^{1,2}$ Nikita BOGATOV, \\ ${ }^{3}$ Flura IL'DARKHANOVA, ${ }^{1}$ Yana SEINA \\ 1Bauman Moscow State Technical University, Moscow, Russia, boldyrev.v.s@bmstu.ru \\ ${ }^{2}$ D. Mendeleev State Technical University, Moscow, Russia, vm uti@muctr.ru \\ ${ }^{3}$ Scientific Production Association «Lakokraspokrytiye», Khotkovo, Moscow region, Russia, mail@npolkp.ru
}

https://doi.org/10.37904/metal.2021.4164

\begin{abstract}
Paint dust is a fire hazardous product, it must be removed as it accumulates in the spray booths. To facilitate cleaning of the inner walls of the chambers, they should be covered with grease or other material and cleaned together with a layer of adhering paint. Currently, there are quite a large number of protective compositions for paint booths. The paper describes the characteristics and disadvantages of modern compositions for protecting the walls of painting chambers. Studies have been carried out on the ability of the composition to be applied to various surfaces and to remove the film from these surfaces after the paintwork has dried, as well as resistance to the action of organic solvents.
\end{abstract}

Keywords: Protective compounds for painting booths, paintwork, colorful dust, organic solvents

\section{INTRODUCTION}

When carrying out painting works, depending on the method of application and the group of complexity of the product, from 40 to $90 \%$ of the paint and varnish material settles on the surface to be painted in the form of a paint and varnish coating (PC). The rest of the paintwork material in the form of paint dust is carried away by the ventilation and settles on the inner walls of the painting booth, gratings, filters, air ducts.

Paint dust is a fire hazardous product, as it accumulates during the operation of painting booths, it must be removed. In accordance with the "Sanitary Rules for Painting with Hand Sprayers", for convenience and ease of cleaning the inner walls of the painting chambers, they should be covered with grease or other material and periodically, at least once a week, cleaned together with a layer of adhered paint.

Currently, more modern protective compositions for paint booths have been developed. For example, the composition of Petronol-OU based on petrochemical raw materials is applied with a brush and removed with scrapers or a solvent. Replacement is done once a month. In foreign practice, water-soluble compositions are used, which are applied easily and quickly with a paint spray gun and form a protective PC on the surface. The formulations are usually washed off with water using a hose or washing machine with a strong stream of water. Examples of such formulations sold in the Russian Federation are OSK 4CR Cabin Protect 7800 wall protection (Gutbier, Germany), CARSYSTEM Booth Mask (for walls) and Dust Keeper (for floors and gratings), (Lechler Coating), RZ -Cocon 9910 / P3-cocoon 9910 (by HENKEL) and others. Domestic developments are the following compounds: PELA tread system (PELA LLC, Nizhny Novgorod), AK-535 and AK-535P compositions, IS-VA composition (TU 301-2044-85), ESKA means (Ecocentre CJSC, Ukraine), solvent-borne varnish XC-567.

The disadvantages of compositions from petrochemical raw materials are significant labor and time costs when cleaning with scrapers or organic solvents [1]. The "ESKA" agent is not recommended for objects with 
increased sensitivity to the action of caustic chemical compounds, it is washed off with water and requires an anti-corrosion PC for painting chambers. Foreign water-soluble compounds are also washed off with water, which creates difficulties in the maintenance of painting booths with dry filters (creates waste of contaminated water) [2-4].

Lacquer XC-567, as a rule, is applied with a layer of gauze for easy removal from the surface.

\section{PRACTICAL PART}

Removable composition Isoflex 7000 (Kluthe $\mathrm{GmbH}$, Germany) also belongs to modern compositions for protecting walls of painting chambers. This composition is designed to protect the plastic and metal surfaces of paint booths from dirt. It is applied by brush and roller as delivered and forms a hard transparent PC, the thickness of which is $20-25 \mu \mathrm{m}$ with a raw PC thickness of $160-200 \mu \mathrm{m}$ and a consumption of $180-240 \mathrm{~g} / \mathrm{m} 2$. The composition can be easily removed using sharp objects. In order to replace imports to protect the walls of painting chambers with dry filters, NPO Lakokraspokrytie has developed and mastered the production of removable water-dispersion varnish VD-AK-5-235 (TU 2332-235-00209711-2008), designed to protect the inner walls of painting cameras from aerosols LMK.

When developing a removable varnish, we used targeted additives Ombrelub RA (release agent), Tafigel PUR 60 (thickener) by Munzing Chemie GmbH (Germany), whose official dealer on the Russian market is CJSC Euro-Color.

When developing a removable varnish, we proceeded from the following premises $[5,6]$ :

- $\quad$ the varnish must be thixotropic to prevent it from dripping from vertical surfaces,

- the varnish should form an elastic paintwork,

- drying temperature should not exceed $30^{\circ} \mathrm{C}$, drying time - $1.5-3$ hours,

- $\quad$ paintwork should be easily removed together with paintwork waste.

As you know, acrylic and PVA dispersions have poor adhesion to metal surfaces. However, poor adhesion to metal does not allow easy peeling of the film from the metal surface. Therefore, when developing the composition, special release agents were investigated.

The most suitable anti-adhesive for removable compositions was the Ombrelub RA anti-adhesive based on liquid hydrocarbons and surfactants, supplied to the Russian market by Euro-Color. Based on this release agent, a removable water-dispersion acrylic varnish was developed and tested.

The technical characteristics of the varnish are given in Table 1.

Table 1 Technical characteristics of removable varnish brand VD-AK-5-235

\begin{tabular}{|c|c|}
\hline Indicator name & Indicator value \\
\hline Appearance and color of varnish & $\begin{array}{l}\text { Homogeneous, viscous milky liquid without lumps and } \\
\text { foreign inclusions }\end{array}$ \\
\hline Coat color and appearance & After drying, the varnish forms a uniform transparent coat \\
\hline Mass fraction of non-volatile substances, $\%$, not less & 40 \\
\hline $\mathrm{pH}$ & $8,0-9,5$ \\
\hline $\begin{array}{c}\text { Viscosity conditions at a temperature of }(20 \pm 0.5)^{\circ} \mathrm{C} \\
\text { according to a VZ-246 viscometer with a nozzle diameter of } \\
6 \mathrm{~mm}, \mathrm{~s} \text {, not less }\end{array}$ & 40 \\
\hline $\begin{array}{c}\text { Drying time at a temperature of }(20 \pm 2)^{\circ} \mathrm{C} \text { to degree } 2 \text {, min, } \\
\text { no more }\end{array}$ & 90 \\
\hline Application Ability & Good \\
\hline Coat peelability & The coat is easily removed from the surface after a cut \\
\hline $\begin{array}{l}\text { Resistance of the coating to static water at a temperature of } \\
\qquad(20 \pm 2)^{\circ} \mathrm{C}, \mathrm{h} \text {, not less }\end{array}$ & 24 \\
\hline
\end{tabular}


Studies were carried out on the ability of the composition to be applied to various surfaces and to remove the film from these surfaces after drying the paintwork, as well as resistance to the action of organic solvents. The research results are shown in Tables 2 and 3. As can be seen from the presented results, the varnish can be applied to painted and unpainted metal surfaces. The film is sufficiently resistant to organic solvents. PC does not drip from a vertical surface with a green film thickness of up to 550 microns, has thixotropic properties with a thixotropy index of 2.72 according to ASTM D 2196.

Table 2 Technological properties of varnish

\begin{tabular}{|c|c|c|}
\hline Type of surface to be painted & Application Ability & Peelable ability \\
\hline Steel 3 & $\begin{array}{l}\text { After drying, a homogeneous transparent film is } \\
\text { formed without coating defects }\end{array}$ & Easily removable \\
\hline Stainless steel & The same & The same \\
\hline Cink Steel & $«$ & $«$ \\
\hline $\begin{array}{c}\text { Steel 3, painted with alkyd-urethane } \\
\text { enamels }\end{array}$ & « & « \\
\hline
\end{tabular}

Table 3 Resistance to organic solvents

\begin{tabular}{|c|c|}
\hline Solvent type & Coat resistance to solvent \\
\hline White Spirit & Slight softening, after drying the paintwork is restored \\
\hline Acetone & Slight softening, after drying the paintwork is restored \\
\hline Xylene & Strong softening, after drying the paintwork is restored, leaving a trace of the solvent \\
\hline Solvent R-4A & Slight softening, after drying the paintwork is restored \\
\hline Solvent R-5A & Strong softening, after drying the paintwork is restored, leaving a trace of the solvent \\
\hline Solvent 646 & Slight softening, after drying the paintwork is restored \\
\hline
\end{tabular}

In Figure 1 shows a fragment of cleaning the inner wall of the painting booth, protected with a removable varnish.

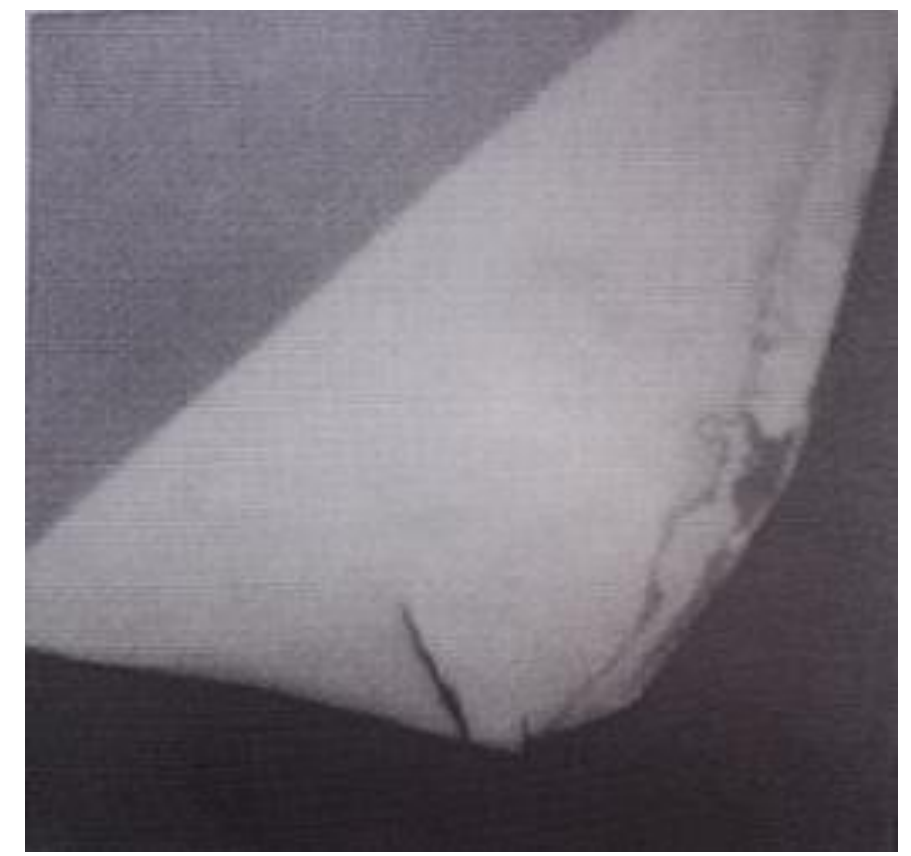

Figure 1 Cleaning the inner wall of the spray booth 


\section{CONCLUSION}

The developed varnish does not contain flammable organic solvents, it is fire and explosion proof during storage and use.

During the initial application of varnish from the surface of walls, windows and seams of the painting booth, it is necessary to remove the accumulation of settled paintwork materials, greases and other solids. Degrease the surface with any technical means and dry. The first degree of degreasing according to GOST 9.402. The varnish is applied by brush, roller or spraying in 2 layers with a wet layer thickness of 150-200 microns.

As a rule, the varnish is applied during the cleaning of the spray booth during non-working hours with the exhaust ventilation operating. Removal of the film with the accumulation of settled paintwork material is made once every 2 weeks or as needed.

\section{REFERENCES}

[1] BOGOMOLOV, B.B., ZUBAREV, A.M., MESHALKIN, V.P., MEN'SHIKOV, V.V., BOLDYREV, V.S. Intelligent logical information algorithm for choosing energy- and resource-efficient chemical technology. Theoretical Foundation of Chemical Engineering. 2019, vol. 53, no. 5, pp. 709-718.

[2] BOLDYREV, V.S., AVERINA, YU.M., MENSHIKOV, V.V., KUZNETSOV, S.V., KOLYBANOV, K.Y. Technological and organization engineering of paint processing. Theoretical Foundation of Chemical Engineering. 2020. vol. 54, no. 3, pp. 420-424.

[3] BOGOSLOVSKII, S.Y., KUZNETSOV, N.N., BOLDYREV, V.S. Parameter optimization of electrolytic process of obtaining sodium hypochlorite for disinfection. Journal of Physics: Conference Series. 2017, vol. 918, no. 1, art. no. 012028.

[4] AVERINA, YU.M., KALYAKINA, G.E., MENSHIKOV, V.V., et al. Neutralisation process design for electroplating industry wastewater containing chromium and cyanides. Herald of the Bauman State Technical University, Series Natural Sciences. 2019, no. 3, p. 70-80.

[5] NELUB, V.A., GORBERG, B.L., GRISHIN, M.V., SARVADII, S.R., SHUB, B.R., BERLIN, A.A., MALYSHEVA, G.V. Properties and technology for applying metal coating to carbon tape. Fibre Chemistry. 2019, vol. 50, no. 6. pp. 524-527.

[6] SHISHLOV, A.V., SAGATELYAN, H.R., SHASHURIN, V.D. Development and implementation of methods and means for achieving a uniform functional coating thickness. Russian Metallurgy (Metall). 2017, vol. 217, no. 13, pp. 1165-1169. 